\title{
An Industry 4.0 Approach for Photovoltaic Plants Monitoring ${ }^{\dagger}$
}

\author{
Miguel Ángel Fernández Fernández ${ }^{1, *}$, Juan Luis Carús Candás ${ }^{1}$, Pablo Barredo Gil ${ }^{1}$, \\ Antonio Miranda de la Torre ${ }^{1}$ and Gabriel Díaz Orueta ${ }^{2}$ \\ 1 TSK, c/Ada Byron, 220, Gijón, 33203 Asturias, Spain; juanluis.carus@grupotsk.com (J.L.C.C.); \\ pablo.barredo@grupotsk.com (P.B.G.); antonio.miranda@grupotsk.com (A.M.d.1.T.) \\ 2 Electrical and Computer Engineering Dept., Spanish University for Distance Education (UNED), 12 Juan \\ del Rosal, 28040 Madrid, Spain; gdiaz@ieec.uned.es \\ * Correspondence: miguelangel.fernandez@grupotsk.com; Tel.: +90-34638844639 \\ + Presented at the 2nd International Research Conference on Sustainable Energy, Engineering, Materials and \\ Environment (IRCSEEME), Mieres, Spain, 25-27 September 2018.
}

Published: 5 November 2018

\begin{abstract}
The exploitation of photovoltaic energy has experienced a great growth worldwide in recent years. Photovoltaic installations are characterized by the presence of a large number of devices and elements. This situation makes the operation and performance of a photovoltaic installation dependent of a large number of parameters and variables. Moreover, due to the size of some photovoltaic installations, a high volume of heterogeneous data is produced. Traditional approaches cannot tackle with such a huge amount of generated data. Through the adoption of a software architecture based on Industry 4.0. Key Enabling Technologies (such as Internet of Things and Big Data, among others), it is possible to improve the monitoring and operation procedures of photovoltaic plants.
\end{abstract}

Keywords: photovoltaic; Industry 4.0; internet of things; Big Data

\section{Introduction}

With the increasingly energy supply, renewable energy generation technologies have emerged as an important alternative to conventional energy. In this field, Photovoltaic systems are having a very rapid development due to their substantial benefits for environment, economy, and energy security. However, it still necessary to research on methods to improve the energy efficiency through a better operation and maintenance of the plant. The control of the efficiency of the electricity production of photovoltaic plants, due to its impact on the profitability, has been defined as a basic need of the operating companies and promoters in this type of facilities [1]. Such efficiency is linked to a multitude of factors that have to be monitored and analyzed to achieve an optimal control. For example, a plant of $18 \mathrm{MWp}$ with an availability rate of $99 \%$ ( $1 \%$ caused by uncontrolled failures) can cause an impact of 156,000.00 euros/year.

In recent years, the industry has undergone a significant development and expansion in both size and complexity. In order to assure effective control over the whole facility, large sensor networks are deployed. However, due to the size of these facilities, monitoring techniques have to deal with a high volume of heterogeneous data whose management implies several technical challenges. Following this, the concept of Industry 4.0 [2] is coined, also known as the fourth industrial revolution, which consists of including innovative Information Technologies (IT) in both the industry and the facilities. In this way, a new concept of Smart Factory is raised through the application of the so-called Key Enabling Technologies (KETs): Big Data for the massive treatment of information, Internet of Things (IoT) and Cloud Computing and Cyber-Physical Systems (among others). 
The present investigation arises with the objective of generating an approximation to the application of KETs in the photovoltaic context, investigating in a processing architecture for advanced analytics in the process of monitoring and operation of photovoltaic plants.

\section{Photovoltaic Plants}

The aim of a photovoltaic plant connected to the network is to capture energy from sunlight and to transform it into electricity, exporting the production to the electricity grid. There are many configurations to build a photovoltaic system, but the following main components can be distinguished:

- Panel or photovoltaic generator. It is the element responsible for capturing and converting solar radiation into direct current (DC) through photovoltaic modules.

- Tracker. Support and orientation structure whose objective is to position the surface of the photovoltaic panel perpendicular to the radiation in real-time, maximizing the energy produced. To do this, it tracks the solar path on the celestial sphere by turning around one or two axes. It is not found in all generation plants because its use is justified in some conditions.

- Strings. Set of panels connected in series, forming a set in which the total voltage is the sum of the individual voltages of each panel. Additionally, the strings are connected in parallel.

- Inverter. Element responsible for transforming the direct current produced by the generator into alternating current (AC), necessary to feed some loads or to be able to be introduced in the electric transport network.

- Meter. Finally, the output of the inverter goes to a counter module whereby the energy produced is counted.

- Weather station. Set of measurement elements whose objective is to monitor the environmental conditions of the plant, since they have a direct impact on the production.

Usually, photovoltaic systems operate continuously and through remote supervision to ensure its operation and maintenance planning, early supervision and maintenance tasks. For this purpose, data collection systems are usually deployed in the plants to gather all the generated data by the photovoltaic elements. Finally, all the generated data are sent to a remote monitoring center. Visualization tools, mainly web or desktop interfaces, are developed to allow operators the visualization of the data though graph generation and data statistics. Related to this, several state-ofthe-art solutions can be found: Green Power Monitor [3], Heliostat [4], Solar Edge [5], SenNet Solar [6] or Webdom [7], among others. They are mainly closed and proprietary platforms that required: (1) the installation and deployment of specific sensors and data collectors in the plant, and (2) the use of a specific visualization tool that sometimes do not match the necessary requirements for the plant operation. Furthermore, these platforms usually have analytical processes to define both performance indicators and alarms, which are very useful to the plant operation but lacking advanced monitoring capabilities. In this context, it is especially important the availability of monitoring tools allowing advanced monitoring techniques and intelligent analysis detecting and preventing failures in a fully automated way [8].

\section{Industry 4.0 Architecture}

KETs technologies have proven in several industrial facilities (manufacturing sector [9], construction [10], maritime industry [11]) identifying both early failures and planning predictive maintenance activities. The use of these novel technologies: (1) increases the reliability of the industrial processes, (2) prevent important damages and (3) allows the generation of new high value-added data.

In this paper, a novel and ubiquitous photovoltaic monitoring system is proposed, which is based on the use of KETs technologies (Figure 1) and handling all the challenges of the current platforms. The proposed solution is based on three main layers. 


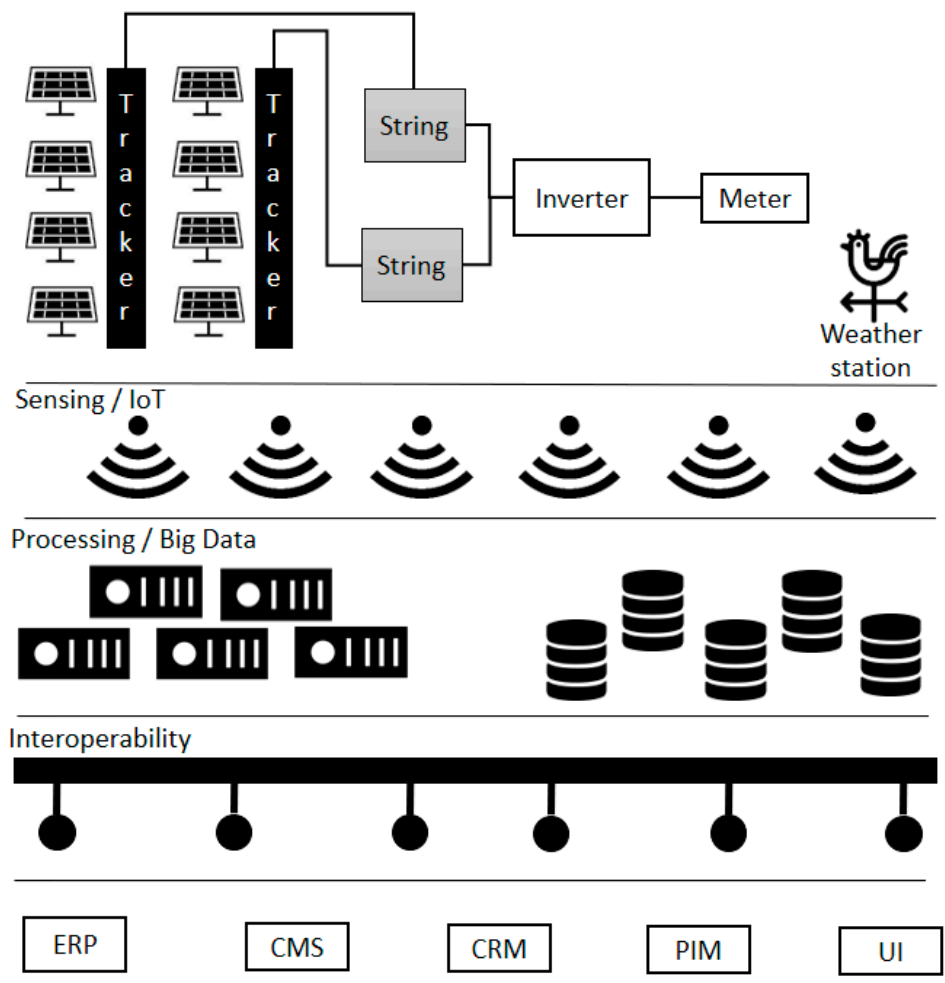

Figure 1. Industry 4.0 architecture deployed in a photovoltaic plant.

\subsection{Sensing}

Many of the components of a photovoltaic plant are capable of transmitting information continuously in connection with their performance or the state of their elements, generating what is technically known as data flow (data streams). Am Internet of Things (IoT) approach is proposed to gather all the data related to the photovoltaic energy generation process. The basic functionality of this layer consists of two modules. The first one is responsible for reading industrial protocols and the second one is responsible for sending the information to the processing layer. In this way, a single and open-source communication interface is created between the plant and the data processing module. This solution should be manufacturer-independent enabling the integration of third parties applications in connection with both data processing and visualization tools. Nowadays, each monitoring platform requires the deployment of specific hardware and software solution to collect data. Therefore, by using an IoT based solution, this limitation is avoided.

\subsection{Processing}

The data processing module is based on Big Data technologies to create a flexible, scalable and distributed system to store and process all the generated data. This module receives the real-time data of the plant and it is hosted on a remote cluster. These technologies will be used to: (1) make an automatic diagnosis of the plant, (2) to predict and analyze the performance and efficiency of the facilities and (3) to manage incidents, alerts and maintenance tasks. Current monitoring systems provide some of these aforementioned features but in a very restricted way. Using Big Data technologies, advances and predictive maintenance activities will be planned. Thanks to the great computational performance capabilities, large sets of historical data can be stored and processed in a hierarchical way, from the individual component level to the aggregated information of the whole plant. Therefore, from an analytical point of view, it is important to enable both real-time and batch processing paradigms. 


\subsection{Interoperability}

An open-data service layer approach is proposed to manage all generated data and to allow the development of specific monitoring tools based on some KETs technologies as virtual or augmented reality. This approach also allows the integration of the generated data with other existent data sources as ERP or CMMS. This layer will also allow functional dynamism, establishing new ways of integrating plant information into external systems. This way, this proposal allows the creation of ad-hoc user interfaces depending on the project and the client needs. Information access should be properly secured, including authentication and authorization policies.

\section{Conclusions}

Summing up, most existing tools currently are limited to capturing and sending data with a basic intelligence, usually based on thresholds or operating ranges. This limitation leads to the need of expert intervention for diagnostic operating. This paper propose a KET based solution to create a comprehensive photovoltaic monitoring system, which should be open-based, scalable, flexible and adaptable to the different user requirements.

Author Contributions: M.A.F.F., J.L.C.C., G.D.O. have been working on the Industry 4.0 architecture. A.M.d.l.T. and P.B.G. have participated in the software proposal.

Conflicts of Interest: The authors declare no conflict of interest.

\section{References}

1. Obi, M.; Bass, R. Trends and challenges of grid-connected photovoltaic systems-A review. Renew. Sustain. Energy Rev. 2016, 58, 1082-1094, doi:10.1016/j.rser.2015.12.289.

2. Hofmann, E.; Rüsch, M. Industry 4.0 and the current status as well as future prospects on logistics. Comput. Ind. 2017, 89, 23-34.

3. Green Power Monitor: Monitoring, Control and Asset Management Solutions. Available online: http://www.greenpowermonitor.com/ (accessed on 5 May 2018).

4. Proxima Systems: Heliostat. Available online: http://www.proximasystems.net/producto/heliostat/ (accessed on 5 May 2018).

5. Solar Edge: A World Leader in Smart Energy. Available online: https://www.solaredge.com/ (accessed on 5 May 2018).

6. SenNet Solar. Available online: http://www.satel-iberia.com/sennet-solar-monitorizacion-remota-deinstalaciones-fotovoltaicas/ (accessed on 5 May 2018).

7. Webdom. Available online: http://www.webdom.es (accessed on 5 May 2018).

8. Triki-Lahiani, A.; Abdelghani, A.B.B.; Slama-Belkhodja, I. Fault detection and monitoring systems for photovoltaic installations: A review. Renew. Sustain. Energy Rev. 2017, 82, 2680-2692.

9. Zhong, R.Y.; Xu, X.; Klotz, E.; Newman, S.T. Intelligent manufacturing in the context of industry 4.0: A review. Engineering 2017, 3, 616-630.

10. Bilal, M.; Oyedele, L.O.; Qadir, J.; Munir, K.; Ajayi, S.O.; Akinade, O.O.; Pasha, M. Big Data in the construction industry: A review of present status, opportunities, and future trends. Adv. Eng. Inform. 2016, 30, 500-521.

11. Wang, H.; Osen, O.L.; Li, G.; Li, W.; Dai, H.N.; Zeng, W. Big data and industrial internet of things for the maritime industry in northwestern Norway. In Proceedings of the TENCON 2015-IEEE Region 10 Conference, Macao, China, 1-4 November 2015; pp. 1-5.

(C) 2018 by the authors. Licensee MDPI, Basel, Switzerland. This article is an open access article distributed under the terms and conditions of the Creative Commons Attribution (CC BY) license (http://creativecommons.org/licenses/by/4.0/). 